\title{
Use of care and the oral health status of people aged 60 years and older in France: results from the National Health and Disability Survey
}

This article was published in the following Dove Press journal:

Clinical Interventions in Aging

31 July 2017

Number of times this article has been viewed

\author{
Gérald Maille ${ }^{1,2}$ \\ Bérengère Saliba-Serre' \\ Anne-Marie Ferrandez' \\ Michel Ruquet ${ }^{1,2}$ \\ 'UMR 7268 ADÉS, Aix-Marseille \\ Université-EFS-CNRS, Faculté \\ de Médecine Nord, ${ }^{2}$ Faculté \\ d'Odontologie, Aix-Marseille \\ Université, Marseille Cedex, France
}

Correspondence: Gérald Maille Faculté d'Odontologie, Aix-Marseille Université, 27 Boulevard Jean Moulin, I3385 Marseille Cedex 5, France Email gerald.maille@univ-amu.fr
Objective: We aimed to analyze, from the data in a national survey, the use of oral care and the oral health status of patients living at home or in an institution.

Background: Patients aged 60 years and older have important oral health needs, but their oral management may differ according to their immediate environment. The fact of living at home or in an institution can influence the use of care and alter the patients' perception of their oral health status.

Methods: The data analyzed were taken from a survey on disability and health carried out in 2008-2009, which is representative of the population living in France. It consists of two sections, one centered on disability and health among home-dwellers and the other on patients living in an institution. In each of these two populations, we carried out descriptive analysis of three themes: use of care, forgoing of care, and oral health.

Results: Although visits to physicians and specialists were frequent, visits to dentists were lower in both populations. While a minority of patients forwent care, it was dental care that was mainly forgone by both home-dwellers and institutionalized patients. The cost factor remained the principal reason, but other factors such as fear or accessibility problems were cited. Use of a dental appliance was considerably more frequent among institutionalized patients than among home-dwellers, with just over half the institutionalized population wearing a dental appliance. Perceived state of oral health remained difficult to interpret.

Conclusion: To improve access to oral care for the elderly, the patients, their entourage and health providers need increased awareness and information on the importance of good oral health. Better information must be associated with regular clinical examination.

Keywords: dental care, health care access, elderly, home-dwellers, community-dwellers, institution, national Disability and Health Survey, France

\section{Background}

The oral health of the elderly is a major public health challenge. The aging population continues to grow under the double effect of increased life expectancy and the advance of the baby boom generation. Patients aged 60 years and older represent $\sim 17 \%$ of the French population, and by 2050, in Europe, this proportion is projected to reach $25 \%-33 \%$ of the total population. ${ }^{1}$

With regard to oral health, the treatment of many dental disorders ${ }^{2-4}$ (caries, periodontal diseases, and missing teeth) is influenced by the patient's ability to cooperate. . $^{5,6}$ These disorders can have a considerable effect on health: ${ }^{7-9}$ poor oral health directly affects nutrition, because of pain, missing teeth, periodontitis, dry mouth, or dysphagia. Pathological microorganisms present in saliva, tartar, caries, deposits on the mucosa, 
and on dentures may be inhaled and cause pneumonia. Microorganisms of oral origin are compounding factors and morbidity cofactors in the elderly. Poor oral health also influences quality of life ${ }^{10,11}$ by causing impairment of self-image and of relationships with others. Age-related disorders and dependence affect oral status either directly ${ }^{12,13}$ or indirectly, as loss of cognitive, motor, and sensory faculties prevents maintenance of good oral hygiene. ${ }^{5,6,14}$ In spite of this objective need of oral management, the dental care consumption of this population is very low and a number of barriers have been identified, which may be either patient- or practitionerrelated ones. ${ }^{15,16}$ These patients' immediate environment and their residential arrangements appear to play a capital role in improving the follow-up of their oral health, and important questions are raised in all developed countries on the quality of care provided by institutions caring for elderly patients, compared in particular with management at home. ${ }^{17,18}$

In France, epidemiological and public health surveys have been carried out most recently in the general population. In the adult population, the rate of use of dental surgeons is $\sim 40 \%$. ${ }^{19}$ However, given the usual public health indicators, there is lack of data on adults' oral health practices, particularly among the elderly. The recent studies are only based on socioeconomic and cultural considerations, as well as the supply of oral health care. ${ }^{20}$ This work analyzes practices among patients aged 60 years and older using an anthropological approach. The distinctive feature of this field study is that it aims to consider each individual in his or her immediate environment. Thus, the principal objective of this study is to analyze the use of oral care and the oral health status of home-dwelling and institutionalized patients aged 60 years and older, based on data from a national survey.

\section{Methods}

\section{Sources}

The source of the data used in this study was the Disability and Health Survey - Ordinary Household Section and Institutions Section, which was performed in 2008 and 2009 by the French National Institute of Statistics and Economic Studies (INSEE) and the French Head Office of Research, Studies, Evaluation and Statistics of the Social Affairs Ministry (DREES).

The authors confirm that all data underlying the findings are fully available without restriction. ${ }^{21}$ These data yielded information on the patients questioned (age, gender, educational level, and level of income), their health status (diseases, use of health care, and prevention), identification of disability (deficits, functional limitations, and restrictions of activity), and lastly, items relating to their social participation and their environment (family environment, presence of family and/or professional caregivers, type of accommodation, accessibility, education, employment, income and benefits, leisure occupations, and perceived discrimination).

The Household Section concerned 29,931 patients who were living at home, representative of the home-dwelling population of metropolitan France and its overseas departments and territories $(62,457,451)$, while the Institutions section included 9,104 institutionalized patients, representative of the institutionalized population of the same areas (636,309), distributed among 1,519 facilities (institutions for adults with disabilities, residential facilities for the dependent elderly, and retirement homes).

The two sections of the survey were explored conjointly to analyze the question of use of care and oral health status through responses to identical questions.

\section{Ethics}

This study was planned as a research project. All precautions were taken by the INSEE to ensure anonymity of the data. This study was declared of public interest by the National Council of Statistical Information and was approved by the French Data Protection Authority (CNIL, French law number 78-17). According to the French law, written informed consent was not required for this type of study.

\section{Sample and study population}

Our study concerned patients aged 60 years and older. Those who were unable to answer all the questions were withdrawn from the study because of too many missing values. We included 9,962 home-dwellers (mean age: 71.77 years, SD: 8.48 years; men: $43.57 \%$ ) and 4,167 institutionalized patients (mean age: 84.21 years, SD: 8.85 years, men $26.73 \%$ ). Three levels of education were stated, distributed as follows: no diploma (26.08\%), non-high school graduate (56.32\%), and high school graduate $(17.60 \%)$ for home-dwellers; and no diploma (44.36\%), non-high school graduate (46.88\%), and high school graduate $(8.76 \%)$ for institutionalized patients.

\section{Questions of interest}

In each of the two populations, we carried out descriptive analysis according to three themes. Several closed questions were put forward on each theme (Tables 1-3).

\section{Use of care}

In the survey questionnaire, use of care was analyzed by three questions, concerning visits to a general practitioner, visits to a specialist, and visits to a dentist. 
Table I Use of care

\begin{tabular}{|c|c|c|}
\hline $\begin{array}{l}\text { Health care } \\
\text { availed }\end{array}$ & $\begin{array}{l}\text { Home-dwellers } \\
(n=9,962), n \text { (\%) }\end{array}$ & $\begin{array}{l}\text { Institutionalized } \\
\text { patients }(n=4,167), n(\%)\end{array}$ \\
\hline \multicolumn{3}{|c|}{$\begin{array}{l}\text { During the past } 12 \text { months, have you personally consulted a general } \\
\text { practitioner at least once? }\end{array}$} \\
\hline Yes & $9,547(94.26)$ & $3,959(97.38)$ \\
\hline No & $4 \mid 4(5.74)$ & 194 (2.62) \\
\hline \multicolumn{3}{|c|}{$\begin{array}{l}\text { During the past } 12 \text { months, have you personally consulted a specialist at } \\
\text { least once? }\end{array}$} \\
\hline Yes & $7,088(66.76)$ & $2,268(50.52)$ \\
\hline No & $2,866(33.24)$ & $1,812(49.48)$ \\
\hline \multicolumn{3}{|c|}{ During the past I 2 months, have you personally consulted a dentist? } \\
\hline Yes & $3,875(46.24)$ & $818(18.49)$ \\
\hline No & $6,074(53.76)$ & $3,225(81.5 I)$ \\
\hline
\end{tabular}

Table 2 Forgoing of care

\begin{tabular}{|c|c|c|}
\hline Factors & $\begin{array}{l}\text { Home-dwellers, } \\
\text { n (\%) }\end{array}$ & $\begin{array}{l}\text { Institutionalized } \\
\text { patients, } \mathbf{n}(\%)\end{array}$ \\
\hline \multicolumn{3}{|c|}{$\begin{array}{l}\text { During the past } 12 \text { months, have you had to forgo medical, surgical, or } \\
\text { dental care even though you really needed it? (HP: } n=9,320 ; \text { IP: } n=3,768 \text { ) }\end{array}$} \\
\hline Yes, several times & $712(5.65)$ & $|4|(3.5)$ \\
\hline Yes, once & $673(6.13)$ & $179(5.33)$ \\
\hline No, never & $7,935(88.22)$ & $3,448(91.17)$ \\
\hline \multicolumn{3}{|c|}{$\begin{array}{l}\text { Regarding the last time you forwent care, did this relate to } \\
\text { (HP: } n=I, 382 ; I P: n=3 \mid 7)\end{array}$} \\
\hline $\begin{array}{l}\text { Hospitalization (including day } \\
\text { hospital or hospital at home) }\end{array}$ & $107(5.24)$ & $22(7.16)$ \\
\hline Dental or orthodontic care & 911 (7I.08) & $227(68.86)$ \\
\hline Visit to a general practitioner & 77 (4.9I) & $18(5.28)$ \\
\hline Visit to a specialist & $287(18.77)$ & $50(18.70)$ \\
\hline \multicolumn{3}{|c|}{$\begin{array}{l}\text { If the last time you forwent care related to dental or orthodontic care, } \\
\text { what was the main reason? (HP: } n=91 I ; \text { IP: } n=227)\end{array}$} \\
\hline $\begin{array}{l}\text { I couldn't afford it (too } \\
\text { expensive, or poorly } \\
\text { reimbursed by my health } \\
\text { insurance) }\end{array}$ & $564(66.30)$ & $72(31.30)$ \\
\hline $\begin{array}{l}\text { The wait to get an } \\
\text { appointment was too long }\end{array}$ & $19(2.77)$ & $3(1.07)$ \\
\hline I didn't have a referral letter & $\mathrm{I}(0.0 \mathrm{I})$ & $0(0)$ \\
\hline I didn't have time & $19(2.26)$ & $\mathrm{I}(0.1 \mathrm{I})$ \\
\hline $\begin{array}{l}\text { I live too far away/there isn't } \\
\text { enough transport/it's too } \\
\text { complicated to get there }\end{array}$ & $49(3.05)$ & $28(12.88)$ \\
\hline $\begin{array}{l}\text { I'm afraid of the dentist and/ } \\
\text { or dental treatment }\end{array}$ & $67(6.68)$ & $35(17.80)$ \\
\hline $\begin{array}{l}\text { I thought l'd wait to see if it } \\
\text { got better on its own }\end{array}$ & $29(4.12)$ & $5(1.17)$ \\
\hline I didn't know a good dentist & $6(0.36)$ & $2(0.33)$ \\
\hline Other reasons & $157(14.45)$ & $80(35.34)$ \\
\hline \multicolumn{3}{|c|}{ Did the treatment you forwent relate to (HP: $n=909 ; \mathrm{IP}: \mathrm{n}=225$ ) } \\
\hline $\begin{array}{l}\text { Placing or maintenance of } \\
\text { a dental prosthesis (bridge, } \\
\text { crown), dentures, or an } \\
\text { orthodontic appliance }\end{array}$ & $624(72.48)$ & $132(58.78)$ \\
\hline Treating a cavity & $141(12.93)$ & $34(11.84)$ \\
\hline $\begin{array}{l}\text { Routine visit to the dentist } \\
\text { or general checkup }\end{array}$ & 144 (14.59) & $59(29.38)$ \\
\hline
\end{tabular}

Abbreviations: HP, home-dwelling patients; IP, institutionalized patients.
Table 3 Perceived and objective oral health

\begin{tabular}{|c|c|c|}
\hline Elements of oral health & $\begin{array}{l}\text { Home-dwellers, } \\
\text { n (\%) }\end{array}$ & $\begin{array}{l}\text { Institutionalized } \\
\text { patients, n (\%) }\end{array}$ \\
\hline \multicolumn{3}{|c|}{ Would you say that the state of your teeth is (HP: $n=9,93$ I; IP: $n=4,042$ ) } \\
\hline Very good & $723(8.74)$ & $132(3.55)$ \\
\hline Good & $3,221(39.04)$ & $\mathrm{I}, 026(27.23)$ \\
\hline Moderately good & $3,265(31.23)$ & $\mathrm{I}, 40 \mathrm{I}(35.35)$ \\
\hline Poor & $\mathrm{I}, 795(14.20)$ & $940(20.85)$ \\
\hline Very poor & 927 (6.79) & $543(13.02)$ \\
\hline \multicolumn{3}{|c|}{ Have you (HP: $n=9,959 ;$ IP: $n=4,026$ ) } \\
\hline All of your own teeth & $265(3.17)$ & $72(1.34)$ \\
\hline $\begin{array}{l}\text { All of your teeth, some of } \\
\text { which have been treated } \\
\text { or replaced }\end{array}$ & $3,020(38.64)$ & $648(14.32)$ \\
\hline Lost some of your teeth & $2,907(29.35)$ & $\mathrm{I}, 234(30.38)$ \\
\hline $\begin{array}{l}\text { Lost all or nearly all of } \\
\text { your teeth }\end{array}$ & $3,767(28.84)$ & $2,072(53.96)$ \\
\hline \multicolumn{3}{|c|}{ If you have not lost all your teeth (HP: $n=6, \mid 77$; IP: $n=I, 9 \mid 6$ ) } \\
\hline \multicolumn{3}{|c|}{ Do you have any of the following tooth problems? } \\
\hline Untreated cavities & $492(4.86)$ & $189(8.19)$ \\
\hline $\begin{array}{l}\text { Loose teeth or receding } \\
\text { gums }\end{array}$ & $974(13.96)$ & $318(12.72)$ \\
\hline Frequent dental abscesses & $122(1.57)$ & $30(1.4)$ \\
\hline None of the above & $4,786(81.70)$ & $1,464(81.19)$ \\
\hline \multicolumn{3}{|c|}{ Do you wear dentures? (HP: $n=9,962 ;$ IP: $n=3,992)$} \\
\hline Yes & $5,150(45.15)$ & $\mathrm{I}, 847(5 \mathrm{I} .5)$ \\
\hline No & $4,812(54.85)$ & $2,145(48.5)$ \\
\hline \multicolumn{3}{|c|}{$\begin{array}{l}\text { Can you bite and chew hard food such as a crisp apple (with your } \\
\text { dentures if worn)? (HP: } n=9,961 ; \text { IP: } n=4,037 \text { ) }\end{array}$} \\
\hline Yes, easily & $5,497(66.85)$ & I,I59 (27.7I) \\
\hline Yes, with some difficulty & $\mathrm{I}, 860(\mathrm{I} 5.77)$ & $725(18.68)$ \\
\hline Yes, with much difficulty & $952(6.5 I)$ & $457(12.03)$ \\
\hline No, I can't & $1,652(10.87)$ & $\mathrm{I}, 696(4 \mathrm{I} .58)$ \\
\hline
\end{tabular}

Note: Because of several possible responses to the question "Do you have any of the following tooth problems", the sum of the percentages is $>100$.

Abbreviations: HP, home-dwelling patients; IP, institutionalized patients.

\section{Forgoing of care}

In the questionnaire, four questions addressed forgoing of care in general and more specifically forgoing of oral care.

Patients who had responded "Yes, several times" or "Yes, once" to the first question "During the past 12 months, have you had to forgo medical, surgical, or dental care even though you really needed it?" went on to the second question. This related to the type of care that had been forgone. For patients who had last forgone dental or orthodontic care, the third question examined the reasons for forgoing care and the fourth questioned the type of dental care that had been forgone.

\section{Perceived and objective oral health}

Five questions assessed perceived oral health, state of dentition, dental problems, denture wearing, and ability to bite and chew. It should be noted that the set of responses related to 
objective oral health is based on the survey responses and not on clinical examination.

\section{Results}

The results are shown in Tables 1-3. "Don't know" responses and refusals to answer any question were not entered in the analyses because of their small number. The percentages given in the tables are weighted percentages.

\section{Use of care}

Visits to a general practitioner during the previous 12 months were very frequent in both populations, at $94.26 \%$ for homedwellers and slightly higher $(97.38 \%)$ for patients living in an institution.

Visits to a specialist were frequent in both populations, but more frequent for home-dwellers $(66.76 \%)$ than for institutionalized patients $(50.52 \%)$.

Visits to dental surgeons were much less frequent in both populations. During the previous 12 months, $46.24 \%$ of home-dwellers had seen a dentist, while this figure fell markedly to $18.49 \%$ for institutionalized patients.

\section{Forgoing of care}

Forgoing of care, for all types of care, concerned only a minority of the two study populations ( $<12 \%$ of homedwellers and $<9 \%$ of institutionalized patients).

When care was forgone, in the majority of cases, this was dental care $(71.08 \%$ of home-dwellers and $68.86 \%$ of institutionalized patients).

When dental care was forgone, home-dwellers explicitly cited three main reasons: cost $(66.3 \%)$, nervousness and fear (6.68\%), and postponement (4.12\%).

Patients living in an institution also cited the economic factor in the first position, but the proportion was lower (only $31.3 \%)$. Fear of the dentist and of dental treatment came second $(17.80 \%)$. Problems of accessibility were cited in the third position (12.88\%).

The type of care that the patients needed and that they had decided to forgo was mainly the placement and/or maintenance of dental appliances $(72.48 \%$ of home-dwellers, $58.78 \%$ of institutionalized patients). This was followed by checkup visits for $14.59 \%$ of home-dwellers and $29.38 \%$ of institutionalized patients. Forgoing of treatment for caries came third, at $\sim 12 \%$ in both populations.

\section{Perceived and objective oral health}

Nearly $48 \%$ of home-dwellers considered that their oral health was "good" or "very good", compared with $31 \%$ of institutionalized patients. Among home-dwellers, 31.23\% perceived their oral health as "moderately good", compared with $35.3 \%$ of institutionalized patients. Oral health was perceived as "poor" or "very poor" by $21 \%$ of home-dwellers but by nearly $34 \%$ of institutionalized patients.

The proportion of patients who stated that they had "lost all or nearly all their teeth" was $28.84 \%$ among home-dwellers and $53.96 \%$ among institutionalized patients. Among homedwellers, $3.17 \%$ stated that they had all their teeth, compared with $1.34 \%$ of institutionalized patients. About 30\% in both populations stated that they had "lost some of their teeth, but had enough to be able to chew without dentures". Lastly, $38.64 \%$ of home-dwellers stated that they had "all their teeth, of which some had been treated or replaced", compared with $14.32 \%$ of institutionalized patients.

The most common dental problems in both populations were loosened teeth (13.96\% of home-dwellers, $12.71 \%$ of institutionalized patients), followed by untreated caries (4.86\% of patients living at home, $8.19 \%$ of institutionalized patients) and frequent dental abscesses in $\sim 1.5 \%$ in both populations. The majority of patients, $>81 \%$, stated that they had none of these dental problems.

While $45.15 \%$ of home-dwellers stated that they wore dentures, the proportion rose to $51.5 \%$ in institutionalized patients.

Nearly $67 \%$ of home-dwellers stated that they could "bite and chew hard foods such as a crisp apple", whereas this was true of only $27.71 \%$ of institutionalized patients. More than $22 \%$ of home-dwellers and $>30 \%$ of institutionalized patients experienced difficulties with the same. Lastly, $10.87 \%$ of home-dwellers and $41.58 \%$ of institutionalized patients declared that they were not able to bite and chew hard foods.

\section{Discussion}

The first part of our study concerned use of care. In both populations, visits to a general practitioner were frequent. This may be explained by the organization of the health system: whereas patients living at home benefit from the network of general practitioners in private practice, in institutions, coordinating physicians are in charge of following up patients and general practitioners visit the patients quite regularly. This health coverage allows efficient referral to specialists, who were visited by $>50 \%$ of both populations. Looking at the use of oral care in patients aged 60 years and older, we observed a distinct decrease, particularly in institutions. Clerc-Urmès et $\mathrm{al}^{22}$ showed that functional limitations and cognitive impairment were barriers to the use of 
dental care in elderly home-dwelling patients. The presence of carers and their awareness with regard to oral health led to improved use of care, enabling the older patient to visit practitioners. For this same population living at home, we suggest that social inequalities and the insufficient density of dental surgeons are major obstacles. The questions of financial resources, health coverage, and the supply of care are thus major issues in access to dental care. ${ }^{23}$ In their study in 2013, Thiébaut et $\mathrm{al}^{24}$ showed that life in an institution could be a barrier to seeking care from a dental surgeon. Considering the results from various previous studies, several reasons could explain the infrequent use of oral care by residents in retirement homes. The management of elderly patients requires an important technical platform and few institutions possess a dental chair in their facility, hindering the provision of oral care. ${ }^{25,26}$ Patients therefore have to travel to a private dental practice and do not always have anyone available to accompany them. Certain fatalism may also be observed in patients who view the deterioration of their oral health as "normal" and age-related and thus consider it as less important than their general health. In addition, the onset of cognitive disorders helps to make these patients less aware of their problems and so to be less demanding of care. ${ }^{27,28}$ Lastly, the nursing staff are not always mindful of the importance of oral health ${ }^{29}$ and are often reticent toward oral care, perceived as unrewarding. ${ }^{30,31}$

Because of this difference between use of care in general and the use of oral care, we considered it important to examine the forgoing of care and its reasons. The second part of our work shows that while forgoing of medical care is fortunately a minority phenomenon, it primarily concerns dental care among both home-dwellers and institutionalized patients. In both our study populations, the economic factor was the main reason. Numerous studies have examined this factor ${ }^{23,32,33}$ and it remains linked to the more general problem, which affects the whole population, of management of oral health in France: oral care costs amount to $€ 10.6$ billion a year, of which $57 \%$ consists of fee surcharges or nonreimbursable care. Since 2008, such care is primarily paid for by supplemental insurers, who bear $39 \%$ of the cost compared with $33 \%$ borne by national health insurance and $25 \%$ by the patients themselves. The result is that in $2012,18 \%$ of the French population abstained from going to the dentist for financial reasons, a percentage that is twice as high as the European mean. ${ }^{34}$

Fear of the dentist or of dental treatments was the second reason for forgoing care, which was cited by both home-dwelling and institutionalized patients. Paradoxically, although fear of the dentist is frequently mentioned, it is little documented. ${ }^{35}$ This aspect tends to be analyzed from the angle of life experience and culture: in a study aiming to identify possible means of reducing the barriers to oral care in older people, Borreani et $\mathrm{al}^{36}$ showed that patients who fear visiting the dentist have a long and complex dental history, and that negative experiences, particularly during childhood, strongly influence their present attitude to dentistry and dental staff.

Whereas home-dwellers placed in third position the postponement of treatment while waiting for their problems to improve, institutionalized patients cited problems of physical accessibility. Several studies have, however, shown that the difficulties that may be faced in accessing oral care in institutions are not restricted to the physical barrier alone, even if this plays a preponderant role. Two kinds of problems can be differentiated: on the one hand, patient-related problems ${ }^{37}$ (difficulties of travel and transport, unavailability of an accompanying patient, and problems of follow-up and screening) and on the other hand, obstacles and barriers related to the health professionals ${ }^{16,26,38}$ (absence of a technical platform, difficulties in management due to poor patient cooperation, and inadequate training of the health care teams).

If we look at the type of care that was required and which the patients had forgone, it is not surprising to see that this was mainly the placement and/or maintenance of dentures. This corresponds to the barrier of cost and the inadequate reimbursement of this type of care by the health coverage system. It affects both populations to varying degrees, which may be related to the patients' socioprofessional category or their standard of living. The type of facility in which they live may also play a role. A recent meta-analysis showed that the legal status of the institution (profit-making or nonprofit-making institutions) could affect the quality of the care given. ${ }^{39}$ On the other hand, forgoing checkup visits or caries treatment cannot be attributed only to the question of cost, as these procedures are normally entirely reimbursed by the health system. The other determinants of forgoing care, already mentioned, then seem to become preponderant.

These first two parts of our study thus lead us to consider that awareness of daily oral hygiene should be considered an important lever for action to promote the health and quality of life of the elderly. Evaluation of oral status and maintenance of good oral hygiene should be an integral part of the medical care given to elderly patients, regardless of their place of residence (their own home, or an institution) and their level of functional autonomy. The health care team, home attendants, caregivers, and the family environment must 
be made aware of the importance of oral health in order to counter the various obstacles that make these patients more likely to forgo oral care.

In the third part of our study, we examined the perceived state of oral health of the patients of both populations. Use of dentures was markedly higher in institutionalized patients than in home-dwellers, with slightly more than half of the patients in institutions wearing them. From the results of the survey, we could not determine whether these were complete or partial dentures, with a view to determining the impact of total edentation on quality of life, although about the same proportion of institutionalized patients stated that they had lost all or nearly all their teeth. Overall, perceived oral health was better in home-dwellers, who more frequently reported "very good" or "good" oral health, than institutionalized patients did, and the former also had better ability to bite and chew without difficulty. The reported number of missing teeth was also higher in institutionalized patients. This may be related to more advanced age on entering an institution, as the health policy aims to keep the elderly in their own homes as long as possible. As institutionalized patients are older, their dental status may be poorer merely because of their greater age. Possibly, a greater degree of autonomy among homedwellers could contribute to eating habits that could help to some extent to avoid malnutrition ${ }^{40}$ and to improve oral comfort. However, in both populations, $>80 \%$ of patients stated that they were free from problems of caries, receding gums and tooth loosening, or dental abscesses, whereas the literature shows that this population has an objective and increasing need for care. These patients appear to lack awareness of their oral status. As pain is often associated with dental problems, if the patient does not feel pain, he or she considers that they have no mouth problems. Possibly, elderly people are unaware of their oral problems if they have been in this condition for a long time and have gradually become used to their disorder, which they now think of as normal in view of their age. It is also possible that they voluntarily underestimate their need for care for the following reasons: fear of dental procedures, cost, or simply to avoid disturbing their routine by going to a dental surgery. Psychotropic medications or impaired cognitive status may also alter their perception of their own health. Lastly, we note that perception of oral health was more often positive in patients with a high educational and income level, as well as in patients who still had their teeth, compared with those who had lost them. ${ }^{41}$ The number of visits to the dentist was predictive of perceived health status. Patients who have lost all their teeth do not consult a dentist and their need for functional rehabilitation, although great, is rarely perceived and expressed. In addition, patients' subjective evaluation of their ability to chew often differs from that of the professionals. ${ }^{42}$

The last part of our study highlighted the difficulty of analyzing expressed perceptions of health. Analysis must necessarily take into account the respondents' personal history and must include full intraoral examination. Negative perception of oral health status may correspond to unmet expectations (pain, discomfort, or difficulty in chewing or swallowing) or to a refusal of problems related to the repercussions of normal aging of the mouth (refusal of loss of teeth, of a dental appliance). Conversely, oral health that is perceived as satisfactory may mask an oral situation that requires specialized management. Regular clinical oral examination of institutionalized patients and home-dwellers aged $>60$ years would certainly ensure early management of and improved oral health.

The data used in our study were taken from the national Disability and Health surveys carried out among patients of all ages living in institutions and in their own homes. These two large structural surveys collected numerous elements relating to functional status (diseases, disabilities, and limitations), restrictions on social participation (access to employment, training and leisure activities, and elements of standard of living), and environmental factors (family, relatives and friends, technical assistance, home alterations, accessibility of public places, and perceived discriminations) reported by individuals in each of the populations. We chose to carry out a descriptive analysis of these results, for patients aged 60 years and older, each in their usual environment, for each of the three themes selected for our study.

Our anthropological approach aimed to consider each individual in his or her immediate environment. The descriptive data demonstrated, in each population, differences in the responses given according to type of residential arrangement. However, it remains indispensable to increase the awareness of health care teams, caregivers, families, and the elderly themselves of the importance of maintaining good oral health if we are to achieve successful aging for all individuals. ${ }^{43}$ Lastly, we note that perception of oral status may be affected by a multitude of emotional, sociocultural, economic, psychological, or physical factors.

\section{Conclusion}

Oral disorders are among the most common chronic conditions worldwide. With advancing age, these disorders become even more significant. Systemic diseases affect oral status, and, conversely, poor oral status adversely affects general 
health. The hygiene and care of the mouths of elderly people are often abandoned because of resignation, loss of cognitive and motor faculties, or sensory loss through decline in the five senses. Although, today, we are aware of the negative impact that oral disorders have on systemic disorders when associated with aging, they are still underestimated and disregarded by the public at large. The factors that restrict the access of elderly patients to oral care appear to be numerous and often interdependent. They are related to insufficient awareness among the elderly themselves and among professionals, as well as institutional causes. It is currently urgent, with a view to prevention, that caregivers, care providers, and the patients themselves should be informed of the benefits to their health of having a healthy mouth. The information given must be accompanied by regular clinical examinations, regardless of the patient's type of residential arrangement.

\section{Disclosure}

The authors report no conflicts of interest in this work.

\section{References}

1. Bontout $\mathrm{O}$, Colin C, Kerjosse R. Personnes âgées dépendantes et aidants potentiels à l'horizon 2040. DREES. Etudes et Résultats. 2002;160. French.

2. Mack F, Mojon P, Budtz-Jorgensen E, et al. Caries and periodontal disease of the elderly in Pomerania, Germany: results of the study of health in Pomerania. Gerodontology. 2004;21(1):27-36.

3. Folliguet M, Veille-Finet A, Tavernier JC, et al. Dental and nutritional status of long-term care institutionalised old adults. Age Nutr. 2004; 15:84-89.

4. Chiappelli F, Bauer J, Spackman S, et al. Dental needs of the elderly in the 21 century. Gen Dent. 2002;50(4):358-363.

5. Frenkel H. Alzheimer's disease and oral care. Dent Update. 2004; 31(5):273-278.

6. Chalmers JM, Carter KD, Spencer AJ. Oral diseases and conditions in community-living older adults with and without dementia. Spec Care Dentist. 2003;23(1):7-17.

7. Pouyssegur V, Precheur I, Sabot JG. Maladies bucco-dentaires: cofacteurs de morbidité des personnes âgées. Rev Geriatr. 2016;41(1):17-31. French.

8. Radoi L, Veille Finet A, Dupuis V, Folliguet M. Impact de l'état bucco-dentaire sur la santé générale: actualisation des connaissances. Rev Geriatr. 2016;41(1):5-16. French.

9. Borgnakke WS. Does treatment of periodontal disease influence systemic disease? Dent Clin North Am. 2015;59(4):885-917.

10. Naito M, Kato T, Fujii W, et al. Effects of dental treatment on the quality of life and activities of daily living in institutionalized elderly in Japan. Arch Gerontol Geriatr. 2010;50(1):65-68.

11. Donnelly LR, Clarke LH, Phinney A, MacEntee MI. The impact of oral health on body image and social interactions among elders in long-term care. Gerodontology. 2016;33(4):480-489.

12. Ghezzi EM, Ship JA. Systemic diseases and their treatments in the elderly: impact on oral health. J Public Health Dent. 2000;60(4):289-296.

13. Singh ML, Papas A. Oral implications of polypharmacy in the elderly. Dent Clin North Am. 2014;58(4):783-796.

14. MacEntee MI. Quality of life as an indicator of oral health in older people. J Am Dent Assoc. 2007;138(suppl):47S-52S.

15. Kossioni AE. Is Europe prepared to meet the oral health needs of older people? Gerodontology. 2012;29(2):e1230-e1240.
16. Bots-VantSpijker PC, Vanobbergen JN, Schols JM, Schaub RM, Bots CP, de Baat C. Barriers of delivering oral health care to older people experienced by dentists: a systematic literature review. Community Dent Oral Epidemiol. 2014;42(2):113-121.

17. Fahey T, Montgomery AA, Barnes J, Protheroe J. Quality of care for elderly residents in nursing homes and elderly people living at home: controlled observational study. BMJ. 2003;326(7389):580.

18. Shah SM, Carey IM, Harris T, Dewilde S, Cook DG. Quality of chronic disease care for older people in care homes and the community in a primary care pay for performance system: retrospective study. BMJ. 2011; 342:d912.

19. L'état de santé de la population en France: Santé bucco-dentaire des adultes. DRESS rapport. 2015:314-315. French.

20. Ménard C, Grizeau-Clemens D, Wemaere J. Santé bucco-dentaire des adultes. Évolutions • N $\mathrm{N}^{\circ}$ 35/Mars 2016. French.

21. Les enquêtes Handicap-Santé (2008-2009) [Internet]. Available from: https://www.insee.fr/fr/metadonnees/source/s1244; https://www.cmh. ens.fr/greco/adisp.php. Accessed April 13, 2017.

22. Clerc-Urmès I, Lupi-Pégurier L, Davin B, Paraponaris A, Fugon L, Ventelou B. Soins buccodentaires et handicaps chez les seniors en France: quel recours et quels freins? Rev Epidemiol Sante Publique. 2012; 60(S2):90. French.

23. Lupi-Pegurier L, Clerc-Urmes I, Abu-Zaineh M, Paraponaris A, Ventelou B. Density of dental practitioners and access to dental care for the elderly: a multilevel analysis with a view on socio-economic inequality. Health Policy. 2011;103(2-3):160-167.

24. Thiébaut S, Lupi-Pégurier L, Paraponaris A, Ventelou A. Comparaison du recours à un chirurgien-dentiste entre les personnes âgées institutionnalisées et celles vivant à domicile, France 2008-2009. Bull Epidémiol Hebd. 2013;7. French.

25. Bots-VantSpijker PC, Bruers JJ, Bots CP, et al. Opinions of dentists on the barriers in providing oral health care to community-dwelling frail older people: a questionnaire survey. Gerodontology. 2016;33(2):268-274.

26. Maille G, Saliba-Serre B, Ferrandez AM, Raskin A, Ruquet M, Le Coz P. Les freins à la prise en charge du patient âgé dépendant en pratique odontologique: le point de vue du praticien. [Barriers to managing elderly dependent patients in the odontological practice: the practitioner's viewpoint]. Rev Geriatr. 2016;41(5):261-269. French.

27. Dounis G, Ditmyer MM, McCants R, Lee Y, Mobley C. Southern Nevada assisted living residents' perception of their oral health status and access to dental care. Gerodontology. 2012;29(2):e150-e154.

28. Kiyak HA, Reichmuth M. Barriers to and enablers of older adults' use of dental services. J Dent Educ. 2005;69(9):975-986.

29. Preston AJ, Kearns A, Barber MW, Gosney MA. The knowledge of healthcare professionals regarding elderly persons' oral care. Br Dent J. 2006;201(5):293-295.

30. Arpin S, Brodeur JM, Corbeil P. Dental caries, problems perceived and use of services among institutionalized elderly in 3 regions of Quebec, Canada. J Can Dent Assoc. 2008;74(9):807.

31. Coleman P. Improving oral health care for the frail elderly: a review of widespread problems and best practices. Geriatr Nurs. 2002;23(4): 189-199.

32. Bedos C, Brodeur JM, Benigeri M, Olivier M. Inégalités sociales dans le recours aux soins dentaires. Rev Epidemiol Sante Publique. 2004; 52(3):261-270. French.

33. Tchicaya A, Lorentz N. Socioeconomic inequalities in the non-use of dental care in Europe. Int J Equity Health. 2014;13:7.

34. Cour des comptes [homepage on the Internet]. Rapport sur la sécurité sociale pour 2016, chapitre VI: les soins bucco-dentaires: une action publique à restaurer, une prise en charge à refonder. Available from: www.ccomptes.fr. Accessed April 13, 2017.

35. Gordon SM, Dionne RA, Snyder J. Dental fear and anxiety as a barrier to accessing oral health care among patients with special health care needs. Spec Care Dentist. 1998;18(2):88-92.

36. Borreani E, Jones K, Scambler S, Gallagher JE. Informing the debate on oral health care for older people: a qualitative study of older people's views on oral health and oral health care. Gerodontology. 2010;27(1):11-18. 
37. Slack-Smith L, Lange A, Paley G, O'Grady M, French D, Short L. Oral health and access to dental care: a qualitative investigation among older people in the community. Gerodontology. 2010;27(2):104-113.

38. Gaszynska E, Szatko F, Godala M, Gaszynski T. Oral health status, dental treatment needs, and barriers to dental care of elderly care home residents in Lodz, Poland. Clin Interv Aging. 2014;9:1637-1644.

39. Comondore VR, Devereaux PJ, Zhou Q, et al. Quality of care in forprofit and not-for-profit nursing homes: systematic review and metaanalysis. BMJ. 2009;339:b2732.
40. Brocker P, Ferry M, Soriano D. Dénutrition à domicile et en EHPAD: le point sur le dépistage et le traitement. Rev Geriatr. 2009;34(7):567-574. French.

41. Ekanayke L, Perera I. Factors associated with perceived oral health status in older individuals. Int Dent J. 2005;55(1):31-37.

42. Bodineau A, Boutelier $\mathrm{C}$, Viala $\mathrm{P}$, et al. Importance de l'hygiène buccodentaire en gériatrie. NPG. 2007;7(40):7-14. French.

43. Kiyak HA. Successful aging: implications for oral health. $J$ Public Health Dent. 2000;60(4):276-281.

\section{Publish your work in this journal}

Clinical Interventions in Aging is an international, peer-reviewed journal focusing on evidence-based reports on the value or lack thereof of treatments intended to prevent or delay the onset of maladaptive correlates of aging in human beings. This journal is indexed on PubMed Central, MedLine,
CAS, Scopus and the Elsevier Bibliographic databases. The manuscript management system is completely online and includes a very quick and fair peer-review system, which is all easy to use. Visit http://www.dovepress. com/testimonials.php to read real quotes from published authors. 